\title{
Neuroprotective agents for neonatal hypoxic-ischemic brain injury
}

Qiaofeng $\mathrm{Wu}^{1,2, \dagger}$, Wu Chen ${ }^{1,3, \dagger}$, Bharati Sinha ${ }^{1,4}$, Yanyang $\mathrm{Tu}^{1}$, Simon Manning ${ }^{5}$, Niranjan Thomas ${ }^{6}$, Shuanhu Zhou ${ }^{7}$, Hong Jiang ${ }^{8}$, He $\mathrm{Ma}^{9}$, Daphne A. Kroessler ${ }^{1}$, Jiemin $\mathrm{Yao}^{9}$, Zhipu $\mathrm{Li}^{8}$, Terry E. Inder ${ }^{5}$ and Xin Wang ${ }^{1, *}$

${ }^{1}$ Department of Neurosurgery, Brigham and Women's Hospital, Harvard Medical School, Boston, Massachusetts 02115, USA

${ }^{2}$ Acupuncture and Moxibustion College, Chengdu University of Traditional Chinese Medicine, Chengdu, Sichuan, 610091, China

${ }^{3}$ Department of Clinical Laboratory, Dongfeng Hospital of Hubei University of Medicine, Shiyan, Hubei, 442012, China

${ }^{4}$ Department of Pediatrics, Boston University School of Medicine, Boston, Massachusetts 02118, USA

${ }^{5}$ Department of Pediatric Newborn Medicine, Brigham and Women's Hospital, Harvard Medical School, Boston, Massachusetts 02115, USA

${ }^{6}$ Department of Neonatology, CMC, Vellore, Tamil Nadu, India

${ }^{7}$ Department of Orthopedic Surgery, Brigham and Women's Hospital, Harvard Medical

School, Boston, Massachusetts 02115, USA

${ }^{8}$ Department of Pediatrics, Qingdao University Medical College, Qingdao, Shangdon 266003, China

${ }^{9}$ Department of Neurosurgery, Third Affiliated Hospital, Guangxi Medical University, Nanning, Guangxi 530031, China

${ }^{*}$ Corresponding author: Wang, X. (xwang@rics.bwh.harvard.edu).

${ }^{\dagger}$ Authors have made equal contributions.

Keywords: Neuroprotective agents; newborns; hypoxic-ischemic brain injury; hypoxicischemic encephalopathy; neuroprotective mechanisms. 
Chemical compounds studied in this article: Xenon (PubChem CID: 23991); antierythropoietin receptor (PubChem CID: 6257657); melatonin (PubChem CID: 896); allopurinol (PubChem CID: 2094); magnesium sulfate (PubChem CID: 24083); topiramate (PubChem CID: 5284627); memantine (PubChem CID: 4054); 2-iminobiotin (PubChem CID: 128878); aminoguanidine (PubChem CID: 2146); indomethacin (PubChem CID: 3715); 7-nitroindazole (PubChem CID: 1893). 
Hypoxic-ischemic ( $\mathrm{H}-\mathrm{I})$ brain injury in newborns is a major cause of morbidity and mortality that claims thousands of lives each year. In this review, we summarize the promising neuroprotective agents tested on animal models and pilot clinical studies of neonatal H-I brain injury according to the different phases of the disease. These agents target various phases of injury including the early phase of excitotoxicity, oxidative stress and apoptosis as well as late-phase inflammatory reaction and neural repair. We analyze the cell survival and cell death pathways modified by these agents in neonatal $\mathrm{H}-\mathrm{I}$ brain injury. We aim to 'build a bridge' between animal trials of neuroprotective agents and potential candidate treatments for future clinical applications against $\mathrm{H}-\mathrm{I}$ encephalopathy. 


\section{Introduction}

With an incidence of between two and six per 1000 live full-term births, perinatal hypoxic-ischemic (H-I) injury is one of the most prevalent causes of neonatal brain injury, leading to death or lifelong disability [1,2]. Although the utility of hypothermia in the reduction of death and disability is now well established in newborns with hypoxicischemic encephalopathy (HIE) [3-7], as many as 40-50\% of children with this condition still die or suffer long-term neurological damage [6,8]. To minimize the neurological consequences of HIE, new and more-effective neuroprotective strategies are urgently required. The complex pathophysiology enables multiple targets at different time points of the disease process. For instance, in the early phase therapies are mainly concentrated on reduction of excitotoxic, oxidative and apoptotic mediators of injury (Figures 1,2 and Table 1), whereas in the later stages reduction of inflammatory cytokines and stimulation of neurotrophic properties in the neonatal brain can be targeted to promote neuronal and oligodendrocyte regeneration (Figure 2).

\section{Early phase}

In this phase the basic cascade of $\mathrm{H}-\mathrm{I}$ brain injury includes hypoxia, ischemia and energy depletion, which results in glutamate excitotoxicity. This in turn causes calcium influx, which triggers a cascade leading to apoptotic cell death via $N$-methyl-D-aspartate (NMDA) and $\alpha$-amino-3-hydroxyl-5-methyl-4-isoxazole-propionate (AMPA) glutamate receptors. With the influx of calcium and other ions, free radicals including superoxide anion $\left(\mathrm{O}_{2}^{-}\right)$, hydroxyl radical $(\mathrm{OH})$, singlet oxygen $\left(\bullet \mathrm{O}_{2}\right)$ and hydrogen peroxide $\left(\mathrm{H}_{2} \mathrm{O}_{2}\right)$ are produced; and lipases, proteases and endonucleases are also activated, triggering a series of cascade reactions resulting in cell death [9]. In addition, the inflammatory process can occur within 3-12 $\mathrm{h}$ after the reperfusion and reoxygenation response and is characterized by production of pro- and anti-inflammatory cytokines [10].

Apoptotic cell death is also involved in newborn $\mathrm{H}-\mathrm{I}$ brain injury, and it has been suggested that, in newborns, apoptosis might be more important in causing cell death after injury than necrosis $[7,11]$. There is growing evidence that apoptosis is important in 
the early phase of $\mathrm{H}-\mathrm{I}$ brain injury and can last for days and even weeks [12]. Mitochondrial impairment, especially damage to mitochondrial membrane integrity, is one of the key processes implicated in apoptotic cell death via the activation of a final executioner of cell death such as caspase 3 [13]. In this phase of neonatal H-I brain injury, the agents described below are applied to combat the pathologic changes and hold great promise for translation to clinical use.

\section{Xenon}

Xenon, a noble gas used as an anesthetic agent, has been shown to be neuroprotective in in vitro and in vivo experimental studies of $\mathrm{H}-\mathrm{I}$ brain injury. It inhibits the NMDA receptor [14] and upregulates the pro-survival proteins Bcl-2 and brain-derived neurotrophic factor (BDNF) to ameliorate injury in asphyxiated rats [15] (Table 1). When combined with hypothermia, xenon offers functional and histopathologic neuroprotection in asphyxiated newborn pigs [16] (Table 1). Observed mechanisms of neuroprotection include preservation of cerebrovascular pressure reactivity, mean arterial blood pressure and cerebral perfusion pressure - independent of the insult severity and seizures [17].

Xenon activates hypoxia-inducible factor $1 \alpha(\mathrm{HIF}-1 \alpha)$ and its downstream effectors erythropoietin (EPO) and vascular endothelial growth factor (VEGF) to provide renal protection in an adult mouse model of ischemia-reperfusion injury [18]. It increases the efficiency of HIF-1 $\alpha$ translation via modulation of the mammalian target of rapamycin (mTOR) pathway [18]. Breathing 50\% xenon for up to $18 \mathrm{~h}$ with $72 \mathrm{~h}$ of cooling is feasible, with no adverse effects seen with 18 months follow-up in a Phase I study in newborns with HIE [19] (Table 2). However, the high cost of xenon and its complicated administration as an inhaled gas requiring intubation and ventilation of the patient are major barriers to its clinical use.

\section{Melatonin}


Melatonin has multiple functions in treating $\mathrm{H}-\mathrm{I}$ brain injury, including antiapoptotic, antioxidative and anti-inflammatory properties. Our studies in in vitro models of brain injury including primary cortical neurons, primary hippocampal neurons and/or primary striatal neurons have shown that melatonin inhibits mitochondrial cell death pathways, including caspase-dependent (cytochrome c/Smac release, caspase 1 and caspase 3 activation) and caspase-independent apoptosis-inducing factor (AIF) cell death pathways [20-23]. Its other protective mechanism is activation of survival signal pathways $[18,19]$. Melatonin has been shown to be neuroprotective in animal models of perinatal $\mathrm{H}-\mathrm{I}$ brain injury [24-26], with long-term effects lasting until adulthood [25] (Table 1). Low-dose melatonin $(0.1 \mathrm{mg} / \mathrm{kg} /$ day $)$ administered to the mother over 7 days at the end of pregnancy protects against the effects of birth asphyxia in an animal model [27] (Table 1). Melatonin is a potent free radical scavenger as well as an indirect antioxidant. The levels of free iron, $\mathrm{F}(2)$-isoprostanes and $\mathrm{F}(4)$-neuroprostanes have been shown to be significantly lower in $\mathrm{H}-\mathrm{I}$ melatonin-treated rats compared with untreated $\mathrm{H}-\mathrm{I}$ animals [28]. At the same time, melatonin stimulates gene expression as well as activates superoxide dismutase (SOD), catalase, G6PD and glutathione reductase in the brain tissue of hypoxic neonatal rats [29] (Table 1). Melatonin in combination with topiramate (TPM; an AMPA/kainite receptor antagonist) significantly reduces brain infarct volume and number of terminal deoxynucleotidyl transferase dUTP nick-end labeling (TUNEL)positive cells in a rat model of $\mathrm{H}-\mathrm{I}$ brain injury [30]. When combined with hypothermia, melatonin enhances neuroprotection by reduction of the $\mathrm{H}-\mathrm{I}$-induced increase in clinically relevant biomarkers in the deep grey matter of newborn piglets [31]. In a study limited by small sample size, there were significant reductions in malondialdehyde and nitrite/nitrate levels in asphyxiated human newborns given melatonin [32]. In recent years, the use of melatonin in human newborns for conditions of oxidative stress such as asphyxia, sepsis and respiratory distress syndrome has demonstrated a good safety profile with no significant complications [33] (Table 2). A randomized control pilot study showed that the combination of melatonin and hypothermia administered to infants with moderate-to-severe $\mathrm{H}-\mathrm{I}$ brain injury was efficacious in reducing oxidative stress and improving survival with favorable neurodevelopmental outcomes at 6 months of age [34] (Table 2). However, concern has been raised with higher doses of melatonin of 10 
$\mathrm{mg} / \mathrm{kg} / \mathrm{h}$ resulting in hypotension in newborn piglets [31]. Also, because there is no licensed intravenous formulation of melatonin available, a study of formulated melatonin cautioned against extrapolation of dosage from adult studies because of differing pharmacokinetic profiles in preterm infants [35].

\section{Erythropoietin}

EPO has recently gained attention as a neuroprotective drug in newborn $\mathrm{H}-\mathrm{I}$ brain injury and, like melatonin, EPO has multiple targets in neuroprotection. It also has antiinflammatory, antioxidant and antiapoptotic properties. EPO inhibits proinflammatory cytokine production induced by lipopolysaccharide (LPS). Administration of exogenous recombinant EPO (rEPO) after $\mathrm{H}-\mathrm{I}$ insult prevents the secondary delayed increase in interleukin (IL)-1 $\beta$ and attenuates the infiltration of leukocytes into the ipsilateral hemisphere [36] (Table 1). EPO and its receptor (EPOR) are expressed in the developing central nervous system and are required for normal brain development. Ligand-bound and unbound EPO regulate the balance of antiapoptotic and proapoptotic gene expression and have inhibitory effects on caspase activation [37] (Table 1). Studies in rats also show that rEPO protects the developing brain via antiapoptotic mechanisms [38] (Table 1) and promotes the health of non-neuronal as well as neuronal cell populations [39]. Coadministration of rEPO conferred neuroprotection by partial restoration of MK801induced reduction of BDNF and glial-cell-line-derived neurotrophic factor (GDNF) as well as enhancement of phosphorylation of extracellular signal-regulated protein kinase $1 / 2(\mathrm{ERK} 1 / 2)$ and Akt [40].

EPO exerts a neuroprotective effect by increasing glutathione peroxidase enzyme activity and decreasing lipid peroxidation levels in $\mathrm{H}-\mathrm{I}$ brain injury in neonatal rats [41] (Table 1). The safety and pharmacokinetics of EPO given in conjunction with hypothermia for newborns with HIE has been established in Phase I trials [42,43] (Table 2). Repeated low-dose rEPO reduced the risk of disability for infants with moderate HIE, without apparent side-effects [44] (Table 2). However, a number of studies also report that EPO administration could have detrimental effects on normal neuronal development. The proliferation of neuronal stem cells elicited by EPO could have a negative impact on 
multipotent progenitor cells [45]. Because the expression of EPO and EPOR is significant during brain development, it is conceivable that exogenous EPO administration could inhibit endogenous EPO expression [46]. In addition, EPO inhibits apoptosis, which could be a necessary physiological component for normal brain development [47].

\section{Allopurinol}

Allopurinol, a xanthine oxidase inhibitor and free radical scavenger, reduces cerebral edema and perinatal $\mathrm{H}-\mathrm{I}$ brain damage in P7 rat pups [48] (Table 1). It provides neuroprotection to hypoxic piglets by increasing brain tissue levels of adenosine and inosine [49] (Table 1). However, a meta-analysis of three clinical trials including 114 infants has failed to show clinically important benefits for newborn infants with HIE [50] (Table 2). The lack of benefit noted in one trial could be the result of selection of severely affected babies and therapy started too late to reduce the early reperfusion-induced freeradical surge [51]. However, even earlier administration of allopurinol by maternal treatment during labor with fetal hypoxia does not significantly lower neuronal damage markers in cord blood, although there might be a beneficial treatment effect specific to girls [52] (Table 2).

\section{NMDA and AMPA receptor antagonists}

Despite concerns that blockage of developmental processes like glutamatergic signaling can harm the developing brain, some NMDA and AMPA receptor antagonists like magnesium sulphate, TPM and memantine have been shown to be neuroprotective in animal models of newborn $\mathrm{H}-\mathrm{I}$ brain injury.

Magnesium sulfate. Magnesium is a naturally occurring NMDA receptor antagonist. It also decreases levels of inflammatory cytokines and platelet aggregation and is essential for glutathione synthesis. In a newborn rat model of $\mathrm{H}-\mathrm{I}$ brain injury, magnesium inhibits apoptotic neuronal death by reduction of caspase 3 or TUNEL-positive cells [53] (Table 1), prevents $\mathrm{H}-\mathrm{I}-\mathrm{induced}$ sensorimotor deficits [54] (Table 1) and significantly reduces 
the percentage of infarcted brain volume and TUNEL positivity, alone or in combination with melatonin [55].

A systematic review of preclinical studies has shown that magnesium is not consistently neuroprotective in perinatal hypoxia-ischemia [56]. A meta-analysis of five clinical randomized control trials (RCTs) where magnesium was given within the first $24 \mathrm{~h}$ after birth in HIE babies as a neuroprotective agent showed improvement in shortterm outcomes without significant increase in adverse effects [57] (Table 2). This supports the need for further adequately powered trials to determine if there are long-term benefits of magnesium and to confirm its safety.

Topiramate. TPM, a widely used anticonvulsant agent, has great potential for neuroprotection owing to its inhibitory action on glutamate receptors, AMPA/kainite receptors [58], as well as voltage-activated $\mathrm{Na}^{+}$and $\mathrm{Ca}^{2+}$ channels. Intraperitoneal or oral pretreatment with TPM reduces brain damage and subsequent cognitive impairments induced by transient hypoxia-ischemia in perinatal rats [59] (Table 1). In a newborn piglet model of $\mathrm{H}-\mathrm{I}$ brain injury, there was a significant reduction of neuronal cell loss in animals treated with TPM, although an increase in apoptosis in the frontal white matter of the drug-treated group was of concern [60] (Table 1). A pilot study to assess the safety and efficacy of TPM in neonates with hypoxic ischemic encephalopathy treated with hypothermia is currently ongoing [61] (Table 2).

Memantine. The clinically available NMDA receptor antagonist memantine attenuates NMDA-evoked currents in developing white-matter oligodendrocytes in a rat model of $\mathrm{H}-\mathrm{I}$ brain injury, reduces the acute loss of developing and mature oligodendrocytes as well as reduces cerebral mantle thickness seen at postnatal day 21 [62] (Table 1). At neuroprotective doses memantine is relatively safe, because it does not increase neuronal apoptosis and has no long-term alterations in the expression of markers of synaptogenesis [63]. 


\section{$N F-\kappa B$ inhibitors}

Tat-NEMO-binding domain peptide. Nuclear factor (NF)- $\kappa \mathrm{B}$ is a ubiquitously expressed transcription factor that regulates apoptotic genes and expression of inflammatory

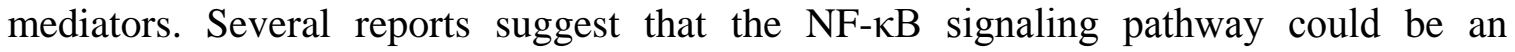
important therapeutic target in infection-sensitized neonatal $\mathrm{H}-\mathrm{I}$ brain injury [64]. However, systemic application of Tat-NEMO-binding domain (TAT-NBD) peptides potent NF- $\mathrm{BB}$ inhibitors - has yielded mixed results in pure models of $\mathrm{H}-\mathrm{I}$ injury that are not sensitized by infection $[65,66]$. TAT-NBD treatment markedly reduces brain injury by preventing mitochondrial accumulation of p53, cytochrome c release and activation of caspase 3 in $\mathrm{H}-\mathrm{I}$ rats [67] (Table 1). Early NF- $\kappa \mathrm{B}$ activation contributes to neonatal $\mathrm{H}-\mathrm{I}$ brain damage, whereas late $\mathrm{NF}-\kappa \mathrm{B}$ activation provides endogenous neuroprotection by upregulation of antiapoptotic molecules like Bcl-2 and Bcl-xL. Therefore, inhibition of early NF- $\kappa B$ activity is neuroprotective only when late NF- $\kappa B$ activity is maintained [68] (Table 1).

PDTC and IDR-1018. Ammonium pyrrolidinedithiocarbamate (PDTC) is neuroprotective in a rat model of $\mathrm{H}-\mathrm{I}$ brain injury by inducing the dephosphorylation of Akt and glycogen synthase kinase- $3 \beta$ and the inhibition of activation and nuclear translocation of NF- $\mathrm{NB}$ and downstream matrix metalloproteinase (MMP)-9 activity [69] (Table 1). In a clinically relevant mouse model, IDR-1018 reduces LPS-induced H-I perinatal brain injury and regulates molecules of inflammatory pathways [70] (Table 1).

\section{Nitric oxide synthase inhibitors}

Owing to the toxic effects of excessive formation of nitric oxide (NO) free radicals in the early reperfusion/reoxygenation phase, inhibition of nitric oxide synthase (NOS) production by selective and non-selective NOS inhibitors could ameliorate perinatal brain 
damage after $\mathrm{H}-\mathrm{I}$ brain injury. In this section we summarize the therapeutic effects of important NOS inhibitors.

2-Iminobiotin. 2-Iminobiotin (2-IB), known for its antioxidative effect, is a selective inhibitor of neuronal NOS (nNOS) and inducible NOS (iNOS). Significant neuroprotection is elicited by reduction of heat shock protein (HSP)70 expression, a marker of brain injury, using 2-IB in 12-day-old rats (P12) following H-I brain injury [71] (Table 1). In addition, the neuroprotective effect of 2-IB is gender-dependent, because it prevents the increase of cytochrome c levels and caspase 3 only in females [72] (Table 1). 2-IB causes reduction in nitrotyrosine, an early marker of cellular injury in perinatal hypoxia-ischemia, via inhibition of nNOS and iNOS. [73]. However, impairment of cognitive functions by 2-IB through nNOS inhibition in adult rats is of concern [74].

Aminoguanidine and indomethacin. Neuroprotection by selective inhibition of iNOS with the iNOS inhibitor aminoguanidine has been reported in several studies in neonatal animals. Aminoguanidine reduces NO production by suppressing the second peak of biphasic increase in NO metabolites, markedly reducing infarct size in a neonatal ischemic rat model [75] (Table 1). Indomethacin, a nonselective cyclooxygenase inhibitor, reduces neonatal rat brain damage after perinatal $\mathrm{H}-\mathrm{I}$ injury. Indomethacin administration before hypoxic ischemia and followed by aminoguanidine is effective in reducing infarct area in newborn rats without an effect on iNOS expression [76] (Table 1). Indomethacin administration after $\mathrm{H}-\mathrm{I}$ brain injury is neuroprotective by inhibition of caspase activity and restoration of glutathione levels, although aggravation of lipid peroxidation-induced ischemia is of concern [77] (Table 1).

7-Nitroindazole and JI-8. Selective inhibition of nNOS with the commonly used nNOS inhibitor 7-nitroindazole and novel nNOS inhibitor JI-8 has been studied in the newborn H-I brain injury model. JI-8 treatment significantly decreases NOS activity (39\%) in fetal rabbit brain homogenates acutely after H-I injury; JI-8 was superior to 7-nitroindazole and a saline vehicle in terms of protective effect on neurobehavior [78] (Table 1).

Nonselective NOS inhibitors such as nitro-L-arginine administered during the early post-H-I period have been reported to reduce free-radical-mediated reperfusion injury in 
the neonatal brain [79]. In P12 rat pups the combined inhibition by nNOS and iNOS reduces $\mathrm{H}-\mathrm{I}$-induced brain injury and improves long-term outcome [80]. An increasing number of studies show that nonselective NOS inhibitors, especially those with prominent inhibitory effects on eNOS, prevent adequate post-H-I brain perfusion, eventually leading to increased production of free radicals and aggravation of brain damage [81].

\section{Later phase}

In the later phase of $\mathrm{H}-\mathrm{I}$ brain injury in newborns, the intrinsic ability of the immature brain to ameliorate damage induced by hypoxia-ischemia is dependent on the activation of inflammatory cytokines, production of trophic factors and endogenous regenerative activity. Cytokines include tumor necrosis factor (TNF)-a, IL-1, IL-6, IL-8 and IL-10; and transcription factors such as NF- $\mathrm{KB}$ and c-Jun N-terminal kinase (JNK) have a central role in this phase [10]. BDNF, epidermal growth factor (EGF), insulin-like growth factor (IGF)-1, VEGF, nerve growth factor (NGF), granulocyte-colony-stimulating factor and other factors such as EPO also have crucial roles. These factors have been reported to exert neuroprotective, antioxidative and antiapoptotic effects and to inhibit the cytotoxicity of excitatory amino acids, stabilize intracellular calcium concentration and suppress calcium overload [82]. Supplementation of deficient growth factors could therefore reduce or prevent delayed $\mathrm{H}-\mathrm{I}$-induced brain damage. In addition, promoting neuronal regeneration with endogenous stem cells or stem cell transplantation is also a possible intervention in neonatal $\mathrm{H}-\mathrm{I}$ brain damage.

\section{Growth factors}

$\boldsymbol{B D N F}$. Pretreatment with BDNF protects against brain injury and spatial memory impairment in $\mathrm{H}-\mathrm{I}$ neonatal rats [83] (Table 1). BDNF protects neural cells from apoptosis by blocking caspase 3 activation and activating neuronal ERK in the neonatal brain. BDNF also supports the survival of existing neurons and encourages the growth 
and differentiation of new neurons and synapses in newborns with H-I brain injury [84]. In addition, because BDNF is a neurotrophin that binds to the TrkB and p75NTR receptors, the TrkB-specific agonist antibody significantly inhibits caspase 3 activation and increases neuronal survival following H-I brain injury [85] (Table 1).

IGF-1. IGF-1, an anabolic pleiotrophic factor, is produced by astrocytes. The neuroprotection effect of IGF-1 is associated with its antiapoptotic and mitogenic effects [86] (Table 1). Delayed administration of IGF-1 rescues oligodendrocyte progenitors in the immature white matter and promotes myelination following $\mathrm{H}-\mathrm{I}$ injury [87] (Table 1). Subcutaneous administration of IGF-1 at 24 and $48 \mathrm{~h}$ of recovery significantly reduces $\mathrm{H}-\mathrm{I}$ injury to immature rat brains and improves long-term memory and cognitive behavior [88]. Further studies infer that the therapeutic effects of IGF-1 probably involve its ability to prevent delayed apoptosis of primary cortical neurons, which means that IGF-1 could be useful not only in the later phases but also in the early phases of $\mathrm{H}-\mathrm{I}$ brain injury [88].

Basic fibroblast growth factor. Basic fibroblast growth factor (bFGF), a polypeptide growth factor, is neuroprotective in $\mathrm{H}-\mathrm{I}$ neonatal rats by preventing NMDA-induced neurotoxicity [89] (Table 1) and upregulating nestin and GAP-43 expression [90,91] (Table 1). In addition, protecting neural cells from apoptosis by upregulating bone morphogenetic protein (BMP)4 was assumed to be another element of the protective effect of bFGF [92]. EGF can stimulate neurogenesis by activation of the endogenous NSCs residing in the subventricular zones and subgranular zone of the dentate gyrus, as shown in rodent pup models [93].

\section{Stem cell therapy}

Stem cell therapy is effective in promoting functional recovery in animal models of neonatal H-I brain injury [94]. Stem cell types used for treating long-term brain damage after neonatal H-I brain injury include neuronal stem cells (NSCs), mesenchymal stem cells (MSCs), embryonic stem cells (ESCs), induced pluripotent stem cells (iPSCs), cord blood stem cells and amniotic fluid stem cells. 
Stimulating endogenous NSCs to differentiate into neurons or transplantation of exogenous NSCs are two potentially important therapies to reduce long-term brain damage after perinatal $\mathrm{H}-\mathrm{I}$ injury. We and other researchers have also reported that the transplantation of umbilical cord blood mononuclear cells regulates the differentiation of endogenous NSCs in H-I neonatal rats via the Hedgehog signaling pathway [95,96]. MSCs are capable of differentiation into a variety of tissue-specific cells. Treatment of ischemic brain injury by transplantation of MSCs in neonatal animal models is effective in reducing lesion volume and improving functional outcome by secretion of several growth factors that are known to contribute to neuroprotection, including colonystimulating factor-1, stem cell factor, VEGF, bFGF, NGF and BDNF, cytokines and other bioactive molecules to regulate damage and repair processes [97] (Table 1). Intracranial administration of MSCs as late as 3-10 days after $\mathrm{H}-\mathrm{I}$ insult reduces histological damage and improves sensorimotor outcome in neonatal mouse and rat models of $\mathrm{H}-\mathrm{I}$ brain injury [98].

The pluripotent capacity of stem cells from human umbilical cord blood allows simultaneous targeting of multiple neuropathologic events initiated by $\mathrm{H}-\mathrm{I}$ insult in animals. Clinical trials of autologous cord blood cells for the treatment of neonatal HIE has established its feasibility and safety [99] (Table 2). Although there are strong preclinical data available that show some types of stem cells are effective neurotherapies, there are still many variables to explore to ensure clinicians can identify the right cells for the right patients at the right time to achieve the overarching goal of improving outcomes for neonates suffering brain injury.

\section{Erythropoietin}

The rather strong neurotrophic capability of EPO is thought to be caused by induction of neural progenitor cell proliferation and prevention of neuronal cell death. EPO induces significant elongation of neurite outgrowth by upregulation of BDNF and the expression of other neurotropic factors [100] (Table 1). It promotes neurogenesis and oligodendrogliosis at early and late time points of neonatal stroke [101]. In addition, the 
multifaceted action of EPO also includes increasing axonal sprouting, revascularization, reducing white matter injury and inducing recovery of structural and functional connectivity of white matter as well as somatosensory cortical function, which are essential for plasticity and remodeling of the injured brain in the late phase of perinatal H-I brain injury $[100,102]$ (Table 1).

\section{Concluding remarks and future challenges}

It is disappointing that, despite the numerous drugs that have proven to be beneficial in animal models, hypothermia is the only intervention against $\mathrm{H}-\mathrm{I}$ brain injury that has translated to clinical use in humans. This gap could be partly due to limitations of preclinical studies in terms of methodological concerns, investigator bias, poor appreciation of drug pharmacokinetics and pharmacodynamics and the possible use of clinically irrelevant models and endpoints. In addition, the choice of species and strains of animals that closely resemble the newborn human brain and its response to injury is lacking. Moreover, the pattern of injury in rodents with relatively small lissencephalic brains with less white matter is different from that of humans. Gender is also a factor, because females appear to benefit more from neuroprotective interventions after $\mathrm{H}-\mathrm{I}$ brain injury, such as hypothermia, EPO and 2-IB [72,103], although some studies showed treatment benefit of EPO in males more than females [104]. It is increasingly clear that exploiting a single pathophysiological pathway might not be sufficient to combat neonatal H-I brain injury. Further studies should be directed toward use of synergistic agents that act on multiple processes that characterize the disease. Promising neuroprotective drugs should be studied in combination with hypothermia, because temperature change can greatly alter the pharmacokinetics and pharmacodynamics of various drugs. Adequate study of the dose-response curve for drugs, evaluating potential therapies in multiple models and with higher species, attention to randomization and blinding of investigators to outcome measures, and more statistical rigor, are some of the measures needed to make preclinical studies more robust to guide clinical trials appropriately. An international panel of experts tasked with deciding which neuroprotective agents are ready for bench-to-bedside translation assigned the highest score to melatonin, followed by EPO, $\mathrm{N}$-acetylcysteine, EPO-mimetics, allopurinol, 
xenon, resveratrol, vitamin C/E, memantine and TPM [105] for postnatal neuroprotection in newborn HIE. We hope that one or more of these promising drugs currently in the initial phases of clinical trials will successfully translate to clinical use in the near future and offer hope to millions of babies with this devastating condition.

\section{Conflicts of interest}

The authors declare that this work contains no potential conflicts in terms of commercial interests.

\section{Acknowledgments}

This work was supported by grants from the Bill \& Melinda Gates Foundation (X. W.), the Muscular Dystrophy Association (X.W.) and the ALS Therapy Alliance (X.W.).

\section{References}

1 De Haan, M. et al. (2006) Brain and cognitive-behavioural development after asphyxia at term birth. Dev. Sci. 9, 350-358

2 Volpe, J.J. (2012) Neonatal encephalopathy: an inadequate term for hypoxicischemic encephalopathy. Ann. Neurol. 72, 156-166

3 Shankaran, S. et al. (2005) Whole-body hypothermia for neonates with hypoxicischemic encephalopathy. N. Engl. J. Med. 353, 1574-1584.

4 Azzopardi, D.V. et al. (2009) Moderate hypothermia to treat perinatal asphyxial encephalopathy. N. Engl. J. Med. 361, 1349-1358

5 Pappas, A. et al. (2015) Cognitive outcomes after neonatal encephalopathy. Pediatrics 135, e624-634

6 Inder, T.E. et al. (2004) Randomized trial of systemic hypothermia selectively protects the cortex on MRI in term hypoxic-ischemic encephalopathy. J. Pediatr. 145, 835-837

7 Ma, H. et al. (2012) Therapeutic hypothermia as a neuroprotective strategy in neonatal hypoxic-ischemic brain injury and traumatic brain injury. Curr. Mol. Med. $12,1282-1296$ 
8 Edwards, A.D. et al. (2010) Neurological outcomes at 18 months of age after moderate hypothermia for perinatal hypoxic ischaemic encephalopathy: synthesis and meta-analysis of trial data. $B M J 340, \mathrm{c} 363$

9 Wassink, G. et al. (2014) The mechanisms and treatment of asphyxial encephalopathy. Front. Neurosci. 8, 40

10 Ferriero, D.M. (2004) Neonatal brain injury. N. Engl. J. Med. 351, 1985-1995

11 Hossain, M.A. (2005) Molecular mediators of hypoxic-ischemic injury and implications for epilepsy in the developing brain. Epilepsy Behav. 7, 204-213

12 Northington, F.J. et al. (2011) Neuronal cell death in neonatal hypoxia-ischemia. Ann. Neurol. 69, 743-758

13 Wang, X. et al. (2011) Targeting caspases in neonatal hypoxia-ischemic brain injury and traumatic brain injury. In Neurodegeneration: Theory, Disorders and Treatments (McNeill, A.S., ed.), pp. 125-134, NOVA

$14 \mathrm{Ma}$, D. et al. (2005) Xenon and hypothermia combine to provide neuroprotection from neonatal asphyxia. Ann. Neurol. 58, 182-193

15 Ma, D. et al. (2006) Xenon preconditioning reduces brain damage from neonatal asphyxia in rats. J. Cereb. Blood Flow Metab. 26, 199-208

16 Chakkarapani, E. et al. (2010) Xenon enhances hypothermic neuroprotection in asphyxiated newborn pigs. Ann. Neurol. 68, 330-341

17 Chakkarapani, E. et al. (2013) Effects of xenon and hypothermia on cerebrovascular pressure reactivity in newborn global hypoxic-ischemic pig model. J. Cereb. Blood Flow Metab. 33, 1752-1760

18 Ma, D. et al. (2009) Xenon preconditioning protects against renal ischemicreperfusion injury via HIF-1alpha activation. J. Am. Soc. Nephrol. 20, 713-720

19 Dingley, J. et al. (2014) Xenon ventilation during therapeutic hypothermia in neonatal encephalopathy: a feasibility study. Pediatrics $133,809-818$

20 Wang, X. et al. (2009) Methazolamide and melatonin inhibit mitochondrial cytochrome $\mathrm{C}$ release and are neuroprotective in experimental models of ischemic injury. Stroke 40, 1877-1885

21 Wang, X. et al. (2011b) The melatonin MT1 receptor axis modulates mutant Huntingtin-mediated toxicity. J. Neurosci. 31, 14496-14507 
22 Wang, X. (2009) The antiapoptotic activity of melatonin in neurodegenerative diseases. CNS Neurosci. Ther. 15, 345-357

23 Wang, X. (2014) The antiapoptotic effects of melatonin in neonatal hypoxicischemic brain injury and adult ischemic stroke. J. Neurosurgery Spine 2, 1033

24 Alonso-Alconada, D. et al. (2013) Neuroprotective effect of melatonin: a novel therapy against perinatal hypoxia-ischemia. Int. J. Mol. Sci. 14, 9379-9395

25 Carloni, S. et al. (2008) Melatonin protects from the long-term consequences of a neonatal hypoxic-ischemic brain injury in rats. J. Pineal. Res. 44, 157-164

26 Carloni, S. et al. (2014) Melatonin reduces endoplasmic reticulum stress and preserves sirtuin 1 expression in neuronal cells of newborn rats after hypoxiaischemia. J. Pineal. Res. 57, 192-199

27 Hutton, L.C. et al. (2009) Neuroprotective properties of melatonin in a model of birth asphyxia in the spiny mouse (Acomyscahirinus). Dev. Neurosci. 31, 437-451

28 Signorini, C. et al. (2009) Free iron, total F-isoprostanes and total F-neuroprostanes in a model of neonatal hypoxic-ischemic encephalopathy: neuroprotective effect of melatonin. J. Pineal. Res. 46, 148-154

29 Eskiocak, S. et al. (2007) The effect of melatonin on protein oxidation and nitric oxide in the brain tissue of hypoxic neonatal rats. Brain Dev. 29, 19-24

30 Ozyener, F. et al. (2012) Neuroprotective effects of melatonin administered alone or in combination with topiramate in neonatal hypoxic-ischemic rat model. Restor. Neurol. Neurosci. 30, 435-444

31 Robertson, N.J. et al. (2013) Melatonin augments hypothermic neuroprotection in a perinatal asphyxia model. Brain 136, 90-105

32 Fulia, F. et al. (2001) Increased levels of malondialdehyde and nitrite/nitrate in the blood of asphyxiated newborns: reduction by melatonin. J. Pineal. Res. 31, 343-349

33 Gitto, E. et al. (2009) Oxidative stress of the newborn in the pre- and postnatal period and the clinical utility of melatonin. J. Pineal. Res. 46, 128-139

34 Aly, H. et al. (2015) Melatonin use for neuroprotection in perinatal asphyxia: a randomized controlled pilot study. J. Perinatol. 35, 186-191

35 Merchant, N.M. et al. (2013) Pharmacokinetics of melatonin in preterm infants. Br. J. Clin. Pharmacol. 76, 725-733 
36 Sun, Y. et al. (2005) Neonatal hypoxia/ischemia is associated with decreased inflammatory mediators after erythropoietin administration. Stroke 36, 1672-1678

37 Kumral, A. et al. (2006) Erythropoietin downregulates bax and DP5 proapoptotic gene expression in neonatal hypoxic-ischemic brain injury. Biol. Neonate 89, 205210

38 Kim, M.S. et al. (2010) The neuroprotective effect of recombinant human erythropoietin via an antiapoptotic mechanism on hypoxic-ischemic brain injury in neonatal rats. Korean J. Pediatr. 53, 898-908

39 Yamada, M. et al. (2011) Erythropoietin protects against apoptosis and increases expression of non-neuronal cell markers in the hypoxia-injured developing brain. $J$. Pathol. 224, 101-109

40 Dzietko, M. et al. (2004) Erythropoietin protects the developing brain against Nmethyl-D-aspartate receptor antagonist neurotoxicity. Neurobiol. Dis. 15, 177-187

41 Kumral, A. et al. (2005) Erythropoietin increases glutathione peroxidase enzyme activity and decreases lipid peroxidation levels in hypoxic-ischemic brain injury in neonatal rats. Biol. Neonate $87,15-18$

$42 \mathrm{Wu}$, Y.W. et al. (2012) Erythropoietin for neuroprotection in neonatal encephalopathy: safety and pharmacokinetics. Pediatrics 130, 683-691

43 Elmahdy, H. et al. (2010) Human recombinant erythropoietin in asphyxia neonatorum: pilot trial. Pediatrics 125, 1135-1142

44 Zhu, C. et al. (2009) Erythropoietin improved neurologic outcomes in newborns with hypoxic-ischemic encephalopathy. Pediatrics 124, 218-226

45 Shingo, T. et al. (2001) Erythropoietin regulates the in vitro and in vivo production of neuronal progenitors by mammalian forebrain neural stem cells. J. Neurosci. 21, 9733-9743

46 Poveshchenko, A.F. et al. (2001) Expression of erythropoietin receptor mRNA in mouse brain hemispheres. Tsitologiia 43, 279-283

47 Tau, G.Z. and Peterson, B.S. (2010) Normal development of brain circuits. Neuropsychopharmacology 35, 147-168

48 Palmer, C. et al. (1993) Allopurinol administered after inducing hypoxia-ischemia reduces brain injury in 7-day-old rats. Pediatr. Res. 33, 405-411 
49 Marro, P.J. et al. (2006) Effect of allopurinol on brain adenosine levels during hypoxia in newborn piglets. Brain Res. 1073-1074, 444-450

50 Chaudhari, T. and McGuire, W. (2012) Allopurinol for preventing mortality and morbidity in newborn infants with hypoxic-ischaemic encephalopathy. Cochrane Database Syst. Rev. 7, Cd006817

51 Benders, M.J. et al. (2006) Early postnatal allopurinol does not improve short term outcome after severe birth asphyxia. Arch. Dis. Child Fetal Neonatal Ed. 91, F163165

52 Kaandorp, J.J. et al. (2015) Maternal allopurinol administration during suspected fetal hypoxia: a novel neuroprotective intervention? A multicentre randomised placebo controlled trial. Arch. Dis. Child Fetal Neonatal Ed. 100, F216-223

53 Canan, T. et al. (2002) Magnesium pre-treatment reduces neuronal apoptosis in newborn rats in hypoxia-ischemia. Brain Res. 955, 133-137

54 Pazaiti, A. et al. (2009) Evaluation of long-lasting sensorimotor consequences following neonatal hypoxic-ischemic brain injury in rats: the neuroprotective role of MgSO4. Neonatology 95, 33-40

55 Cetinkaya, M. et al. (2011) Possible neuroprotective effects of magnesium sulfate and melatonin as both pre- and post-treatment in a neonatal hypoxic-ischemic rat model. Neonatology 99, 302-310

56 Galinsky, R. et al. (2014) Magnesium is not consistently neuroprotective for perinatal hypoxia-ischemia in term-equivalent models in preclinical studies: a systematic review. Dev. Neurosci. 36, 73-82

57 Tagin, M. et al. (2013) Magnesium for newborns with hypoxic-ischemic encephalopathy: a systematic review and meta-analysis. J. Perinatol. 33, 663-669

58 Follett, P.L. et al. (2004) Glutamate receptor-mediated oligodendrocyte toxicity in periventricular leukomalacia: a protective role for topiramate. J. Neurosci. 24, 44124420

59 Noh, M.R. et al. (2006) Neuroprotective effect of topiramate on hypoxic ischemic brain injury in neonatal rats. Exp. Neurol. 201, 470-478

60 Schubert, S. et al. (2005) Neuroprotective effects of topiramate after hypoxiaischemia in newborn piglets. Brain Res. 1058, 129-136 
61 Filippi, L. et al. (2012) Safety and efficacy of topiramate in neonates with hypoxic ischemic encephalopathy treated with hypothermia (NeoNATI). BMC Pediatr. 12, 144

62 Manning, S.M. et al. (2008) NMDA receptor blockade with memantine attenuates white matter injury in a rat model of periventricular leukomalacia. J. Neurosci. 28, $6670-6678$

63 Manning, S.M. et al. (2011) The clinically available NMDA receptor antagonist, memantine, exhibits relative safety in the developing rat brain. Int. J. Dev. Neurosci. $29,767-773$

64 Yang, D. et al. (2013) Intranasal delivery of cell-penetrating anti-NF-kB peptides (Tat-NBD) alleviates infection-sensitized hypoxic-ischemic brain injury. Exp. Neurol. 247, 447-455

65 Van den Tweel, E.R. et al. (2006) Selective inhibition of nuclear factor-kappaB activation after hypoxia/ischemia in neonatal rats is not neuroprotective. Pediatr. Res. $59,232-236$

66 Nijboer, C.H. et al. (2008) A dual role of the NF-kappaB pathway in neonatal hypoxic-ischemic brain damage. Stroke 39, 2578-2586

67 Nijboer, C.H. et al. (2008) Strong neuroprotection by inhibition of NF-kappaB after neonatal hypoxia-ischemia involves apoptotic mechanisms but is independent of cytokines. Stroke 39, 2129-2137

68 Nijboer, C.H. et al. (2009) Alternate pathways preserve tumor necrosis factor-alpha production after nuclear factor-kappaB inhibition in neonatal cerebral hypoxiaischemia. Stroke 40, 3362-3368

69 Nurmi, A. et al. (2006) Antioxidant pyrrolidinedithiocarbamate activates Akt-GSK signaling and is neuroprotective in neonatal hypoxia-ischemia. Free Radic. Biol. Med. 40, 1776-1784

70 Bolouri, H. et al. (2014) Innate defense regulator peptide 1018 protects against perinatal brain injury. Ann. Neurol. 75, 395-410

71 van den Tweel, E.R. et al. (2005) Long-term neuroprotection with 2-iminobiotin, an inhibitor of neuronal and inducible nitric oxide synthase, after cerebral hypoxiaischemia in neonatal rats. J. Cereb. Blood Flow Metab. 25, 67-74

72 Nijboer, C.H. et al. (2007) Gender-specific neuroprotection by 2-iminobiotin after hypoxia-ischemia in the neonatal rat via a nitric oxide independent pathway. $J$. Cereb. Blood Flow Metab. 27, 282-292 
73 Zhu, C. et al. (2004) Nitrosylation precedes caspase-3 activation and translocation of apoptosis-inducing factor in neonatal rat cerebral hypoxia-ischaemia. J. Neurochem. $90,462-471$

74 Utkan, T. et al. (2012) Selective and nonselective neuronal NOS inhibitors impair cognitive function in the three panel runway and passive avoidance tasks in rats. Pharmacol. Biochem. Behav. 101, 515-519

75 Tsuji, M. et al. (2000) Protective effect of aminoguanidine on hypoxic-ischemic brain damage and temporal profile of brain nitric oxide in neonatal rat. Pediatr. Res. $47,79-83$

76 Tutak, E. et al. (2005) Neuroprotective effects of indomethacin and aminoguanidine in the newborn rats with hypoxic-ischemic cerebral injury. Neurochem. Res. 30, 937-942

77 Taskin, E. et al. (2009) The effects of indomethacin on caspases, glutathione level and lipid peroxidation in the newborn rats with hypoxic-ischemic cerebral injury. Brain Res. 1289, 118-123

78 Yu, L. et al. (2011) Neuronal nitric oxide synthase inhibition prevents cerebral palsy following hypoxia-ischemia in fetal rabbits: comparison between JI-8 and 7nitroindazole. Dev. Neurosci. 33, 312-319

79 Fabian, R.H. et al. (2008) Perivascular nitric oxide and superoxide in neonatal cerebral hypoxia-ischemia. Am. J. Physiol. Heart Circ. Physiol. 295, H1809-1814

80 Van den Tweel, E.R. et al. (2002) Inhibition of nNOS and iNOS following hypoxiaischaemia improves long-term outcome but does not influence the inflammatory response in the neonatal rat brain. Dev. Neurosci. 24, 389-395

81 Cimino, M. et al. (2005) Neuroprotective effect of simvastatin in stroke: a comparison between adult and neonatal rat models of cerebral ischemia. Neurotoxicology 26, 929-933

82 Ara, J. et al. (2011) Hypoxic-preconditioning induces neuroprotection against hypoxia-ischemia in newborn piglet brain. Neurobiol. Dis. 43, 473-485

83 Almli, C.R. et al. (2000) BDNF protects against spatial memory deficits following neonatal hypoxia-ischemia. Exp. Neurol. 166, 99-114

84 Imam, S.S. et al. (2009) Cord blood brain derived neurotrophic factor: diagnostic and prognostic marker in full term newborns with perinatal asphyxia. Pak. J. Biol. Sci. 12, $1498-1504$ 
85 Kim, G.S. et al. (2014) TrkB agonist antibody pretreatment enhances neuronal survival and long-term sensory motor function following hypoxic ischemic injury in neonatal rats. PLoS One 9, e88962

86 Lin, S. et al. (2005) IGF-1 protects oligodendrocyte progenitor cells and improves neurological functions following cerebral hypoxia-ischemia in the neonatal rat. Brain Res. 1063, 15-26

87 Wood, T.L. et al. (2007) Delayed IGF-1 administration rescues oligodendrocyte progenitors from glutamate-induced cell death and hypoxic-ischemic brain damage. Dev. Neurosci. 29, 302-310

88 Zhong, J. et al. (2009) Delayed IGF-1 treatment reduced long-term hypoxia-ischemiainduced brain damage and improved behavior recovery of immature rats. Neurol. Res. $31,483-489$

89 Nozaki, K. et al. (1993) Basic fibroblast growth factor protects against hypoxiaischemia and NMDA neurotoxicity in neonatal rats. J. Cereb. Blood Flow Metab. 13, $221-228$

90 Peng, H. et al. (2006) Effect of basic fibral growth factor on nestin expression in neonatal rats following hypoxic-ischemic brain damage. Zhongguo Dang Daierkezazhi 8, 235-238

91 Sun, J.Q. et al. (2007) Neuroprotective effects of exogenous basic fibroblast growth factor on the hypoxic-ischemic brain damage of neonatal rats. Zhonghua $\mathrm{Er} \mathrm{Ke} \mathrm{Za}$ Zhi 45, 354-359

92 Yin, X.J. et al. (2009) Effect of basic fibroblast growth factor on expression of protein and mRNA of bone morphogenetic protein 4 in hypoxic-ischemic brain damage in newborn rats. Zhonghua Er Ke Za Zhi 47, 856-861

93 Alagappan, D. et al. (2009) Brain injury expands the numbers of neural stem cells and progenitors in the SVZ by enhancing their responsiveness to EGF. ASN. Neuro. doi: 10.1042/AN20090002

94 Chicha, L. et al. (2014) Stem cells for brain repair in neonatal hypoxia-ischemia. Childs Nerv. Syst. 30, 37-46

95 Wang, X. et al. (2014). Umbilical cord blood cells regulate the differentiation of endogenous neural stem cells in hypoxic ischemic neonatal rats via the hedgehog signaling pathway. Brain Res. 1560, 18-26 
96 Wang, X.L. et al. (2013) Umbilical cord blood cells regulate endogenous neural stem cell proliferation via hedgehog signaling in hypoxic ischemic neonatal rats. Brain Res. $1518,26-35$

97 van Velthoven, C.T. (2010) Nasal administration of stem cells: a promising novel route to treat neonatal ischemic brain damage. Pediatr. Res. 68, 419-422

98 Zhao, L.R. et al. (2002) Human bone marrow stem cells exhibit neural phenotypes and ameliorate neurological deficits after grafting into the ischemic brain of rats. Exp. Neurol. 174, 11-20

99 Cotton, C.M. et al. (2014) Feasibility of autologous cord blood cells for infants with hypoxic-ischemic encephalopathy. J. Pediatr. 164, 973-979

100 Fan, X. et al. (2011) Beneficial effect of erythropoietin on sensorimotor function and white matter after hypoxia-ischemia in neonatal mice. Pediatr. Res. 69, 56-61

101 Gonzalez, F.F. et al. (2013) Erythropoietin increases neurogenesis and oligodendrogliosis of subventricular zone precursor cells after neonatal stroke. Stroke 44, $753-758$

102 Jantzie, L.L. et al. (2013) Erythropoietin signaling promotes oligodendrocyte development following prenatal systemic hypoxic-ischemic brain injury. Pediatr. Res. $74,658-667$

103 Fan, X. et al. (2013) Hypothermia and erythropoietin for neuroprotection after neonatal brain damage. Pediatr. Res. 73, 18-23

104 Fang, A.Y. et al. (2013) Effects of combination therapy using hypothermia and erythropoietin in a rat model of neonatal hypoxia-ischemia. Pediatr. Res. 73, 12-17

105 Robertson, N.J. et al. (2012) Which neuroprotective agents are ready for bench to bedside translation in the newborn infant? J. Pediatr. 160, 544-552

\section{Figure legends}

Figure 1. The classification of present neuroprotective agents for early treatment of neonatal hypoxic-ischemic brain injury. These agents are classified into four categories according to currently known mechanisms: antiexcitotoxicity, antioxidation, antiinflammation and antiapoptosis. Xenon and Tat-NEMO-binding domain (TAT-NBD) peptides have two therapeutic effects. Melatonin and erythropoietin (EPO) have three 
therapeutic effects. Abbreviations: PDTC, ammonium pyrrolidinedithiocarbamate; IDR1018 , innate defence regulator-1018 peptide.

Figure 2. Molecular mechanisms involved in neonatal hypoxic-ischemic $(\mathrm{H}-\mathrm{I})$ brain injuries and molecular targets for present drug developments. Pathogenesis is chronologically divided into three stages: early phase, reperfusion and later phase. In the early phase, energy deprivation caused by hypoxia-ischemia triggers a failure of ATPdependent $\mathrm{Na}^{+}-\mathrm{K}^{+}$pump, leading to intracellular accumulation of $\mathrm{Na}^{+}, \mathrm{Ca}^{2+}$ and water, which results in cytotoxic edema and acute necrosis. At same time, hypoxia-ischemia induces the transcription of inflammation factors and neurotrophic factors for later-phase repair by the hypoxia-inducible factor (HIF)-1 $\alpha$ pathway. The accumulation of glutamate caused by impaired reuptake from presynapsis leads to depolarization of cell membrane, increasing the influx of $\mathrm{Ca}^{2+}$ from the intracellular endoplasmic reticulum (ER) and mitochondrion, which in turn activates the intrinsic caspase-dependent apoptosis pathway. Excessive cytoplasmic $\mathrm{Ca}^{2+}$ also activates the expression of proinflammatory genes, such as interleukins (ILs) and tumor necrosis factor (TNF)- $\alpha$, by the nuclear factor (NF)-kB pathway. Reoxygenation during reperfusion produces substantial radical oxygen species (ROS), radical nitrogen species (RNS) and peroxynitrite $\left(\mathrm{ONOO}^{-}\right)$, which exacerbates the damage to the cell membrane and DNA and induces cell apoptosis. In the later phase the proinflammatory factors expressed in the early phase activate an extrinsic caspase-independent apoptosis pathway and attenuate neuronal injury. The neurotrophic factors activate a protective pro-survival pathway by AKT/protein kinase B (PKB). The molecular targets of the agents described in this paper are framed in orange. Abbreviations: APAF1, apoptosis protease activating factor-1; BAK, Bcl-2 agonist killer 1; BAX, Bcl-2-associated X protein; BID, BH3 interacting domain death; Cyto.C, cytochrome C; IKK, inhibitor of nuclear factor kappa-B kinase; CaM, calmodulin; FADD, FAS-associated death domain; cFLIP, cellular Fas-associated death domain-like interleukin-1 $\beta$-converting enzyme (FLICE)-like inhibitory protein; $\mathrm{IkB} \alpha$, inhibitory subunit of nuclear factor kappa B alpha; pJNK1, c-Jun amnion terminal kinase 1; PKC, protein kinase C; SMAC/DIABLO, second-mitochondrial-derived activator of caspases; TRAF2, TNF-receptor-associated factor-2; PHD2, prolyl hydroxylase domainprotein 2; 
VHL-E3, von Hippel-Lindau ligase; EPO, erythropoietin; VEGF, vascular endothelial growth factor; AIF, apoptosis-inducing factor. 


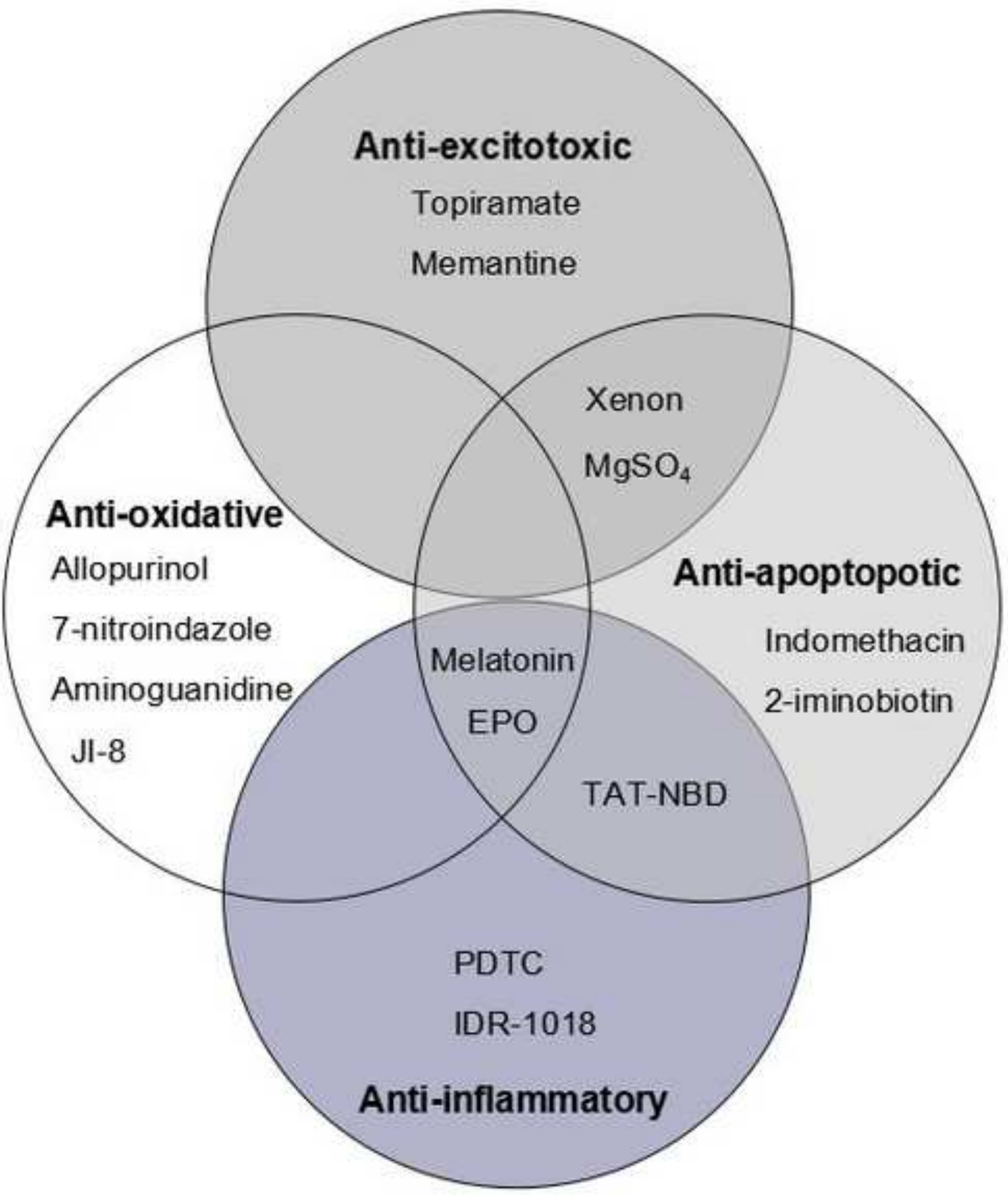




\section{Early phase}

(Hypoxia-ischemia)

\section{Reperfusion phase}

(oxidation and injuries)

\section{Later phase}

(Inflammation and Repair)

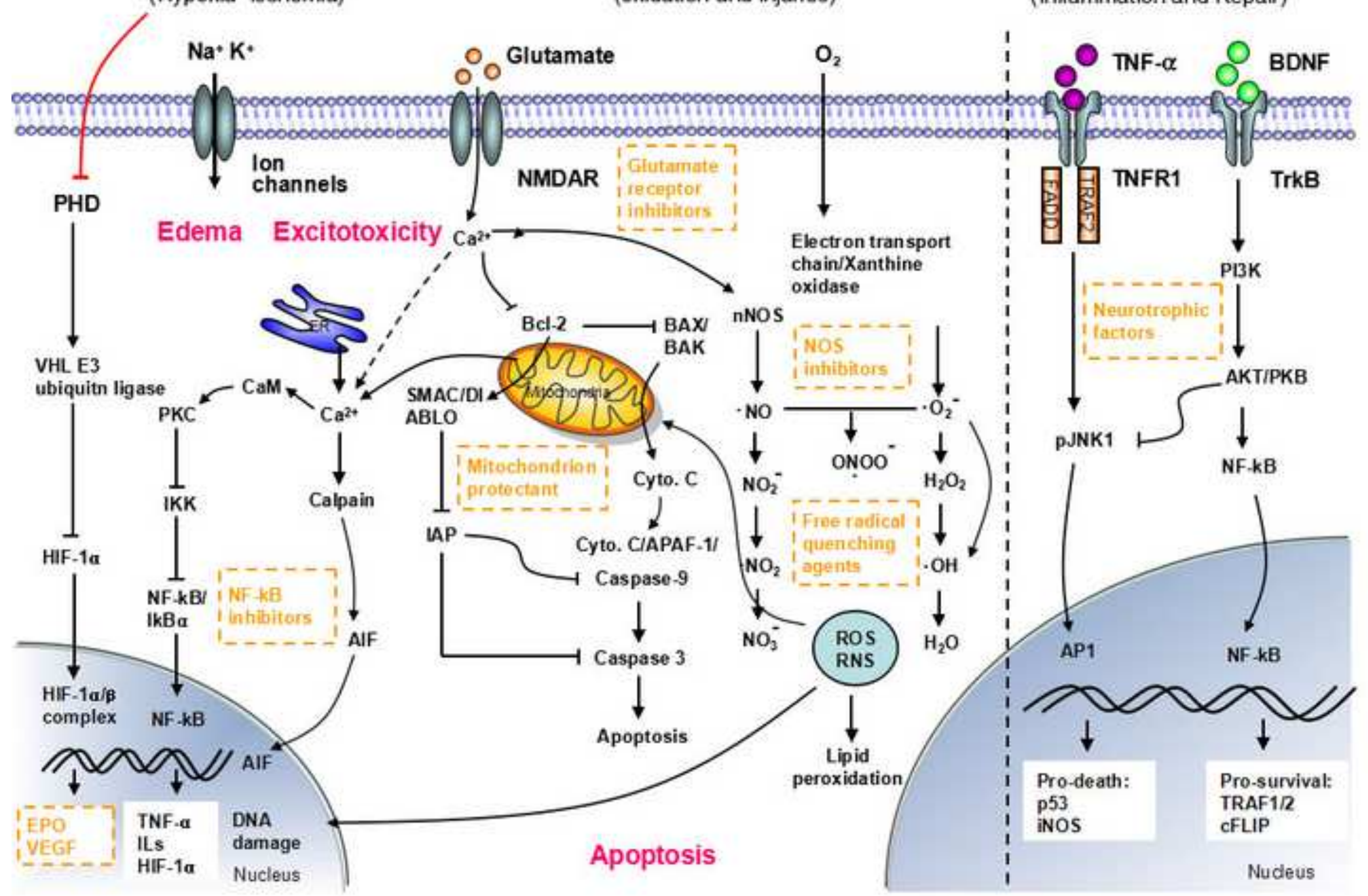


Table 1. Neuroprotective agents and mechanisms in animal models of neonatal hypoxic-ischemic brain injury

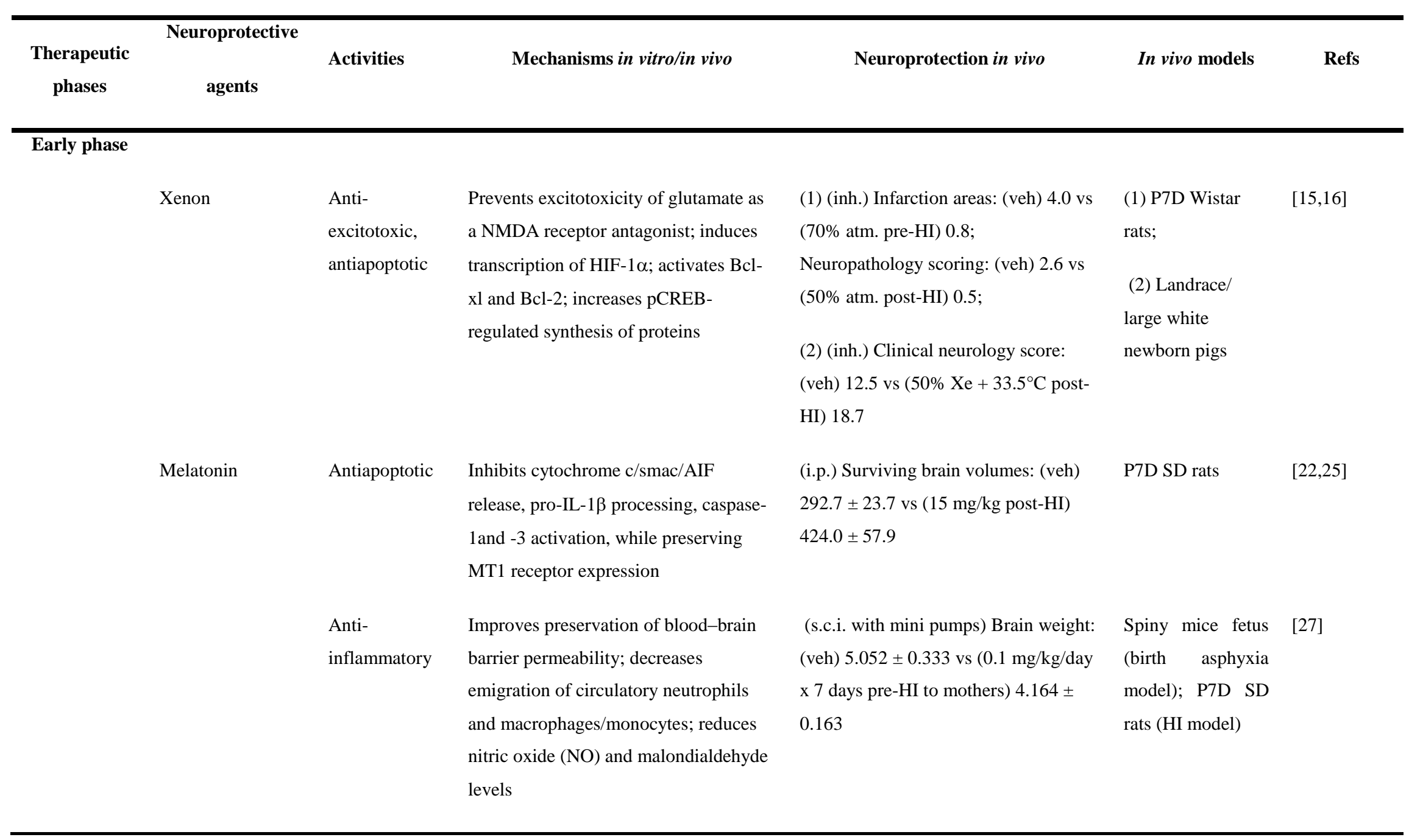




\begin{tabular}{|c|c|c|c|c|c|}
\hline & Antioxidative & $\begin{array}{l}\text { Stimulates gene expression and } \\
\text { activation of SOD, catalase, G6PD and } \\
\text { glutathione reductase; maintains low } \\
\text { levels of free iron, } \mathrm{F}(2) \text {-isoprostanes, } \\
\text { and } \mathrm{F}(4) \text {-neuroprostanes }\end{array}$ & $\begin{array}{l}\text { (i.p.) Advanced oxidation protein } \\
\text { products: (veh) } 7.3 \pm 1.6 \mathrm{vs}(10 \mathrm{mg} / \mathrm{kg} \\
\text { x } 3 \text { pre- and post-HI) } 5.1 \pm 1.5\end{array}$ & P7D SD rats & [29] \\
\hline \multirow[t]{3}{*}{ EPO } & $\begin{array}{l}\text { Anti- } \\
\text { inflammatory }\end{array}$ & $\begin{array}{l}\text { Prevents secondary, delayed rise in IL- } \\
1 \beta \text { and attenuates the infiltration of } \\
\text { leukocytes }\end{array}$ & $\begin{array}{l}\text { (i.p.) Surviving brain areas: (veh) } 41 \% \\
\text { vs ( } 5 \mathrm{U} / \mathrm{g} \text { post-HI) } 84 \%\end{array}$ & P7D SD rats & [36] \\
\hline & Antiapoptotic & $\begin{array}{l}\text { Binds EPOR and activates survival } \\
\text { signaling pathways by reducing the } \\
\text { expressions of Bax and Bax/Bcl-2 ratio } \\
\text { and increasing Bcl-2 level }\end{array}$ & $\begin{array}{l}\text { (1) (i.p.) Neuronal density of } \\
\text { dentate gyrus of hippocampus: (veh) } \\
48.66 \pm 4.32 \text { vs ( } 1000 \mathrm{U} / \mathrm{kg} / \text { day x } 5 \\
\text { post-HI) } 65.01 \pm 3.25 \text {; } \\
\text { (2) (i.p.) Surviving brain areas: (veh) } \\
68.6 \% \text { ) vs (1000 U/kg pre-HI) } 94.3 \% \\
\text { and (post-HI) } 81.4 \%\end{array}$ & $\begin{array}{l}\text { (1) P5D Wistar } \\
\text { rats; } \\
\text { (2) P7D SD rats }\end{array}$ & {$[37,38]$} \\
\hline & Antioxidative & $\begin{array}{l}\text { Increases glutathione peroxidase } \\
\text { enzyme activity and decreases lipid } \\
\text { peroxidation levels }\end{array}$ & & P7D Wistar rats & {$[41]$} \\
\hline Allopurinol & Antioxidative & $\begin{array}{l}\text { Chelates free ferric ion and cupric ion } \\
\text { and scavenges hydroxyl radicals. }\end{array}$ & $\begin{array}{l}\text { (s.c.i.) Gross neuropathologic grading: } \\
\text { (veh) } 16 \text { normal vs }(135 \mathrm{mg} / \mathrm{kg} \text { post- } \\
\text { HI) } 8 \text { normal }\end{array}$ & P7D Wistar rats & {$[48,49]$} \\
\hline
\end{tabular}




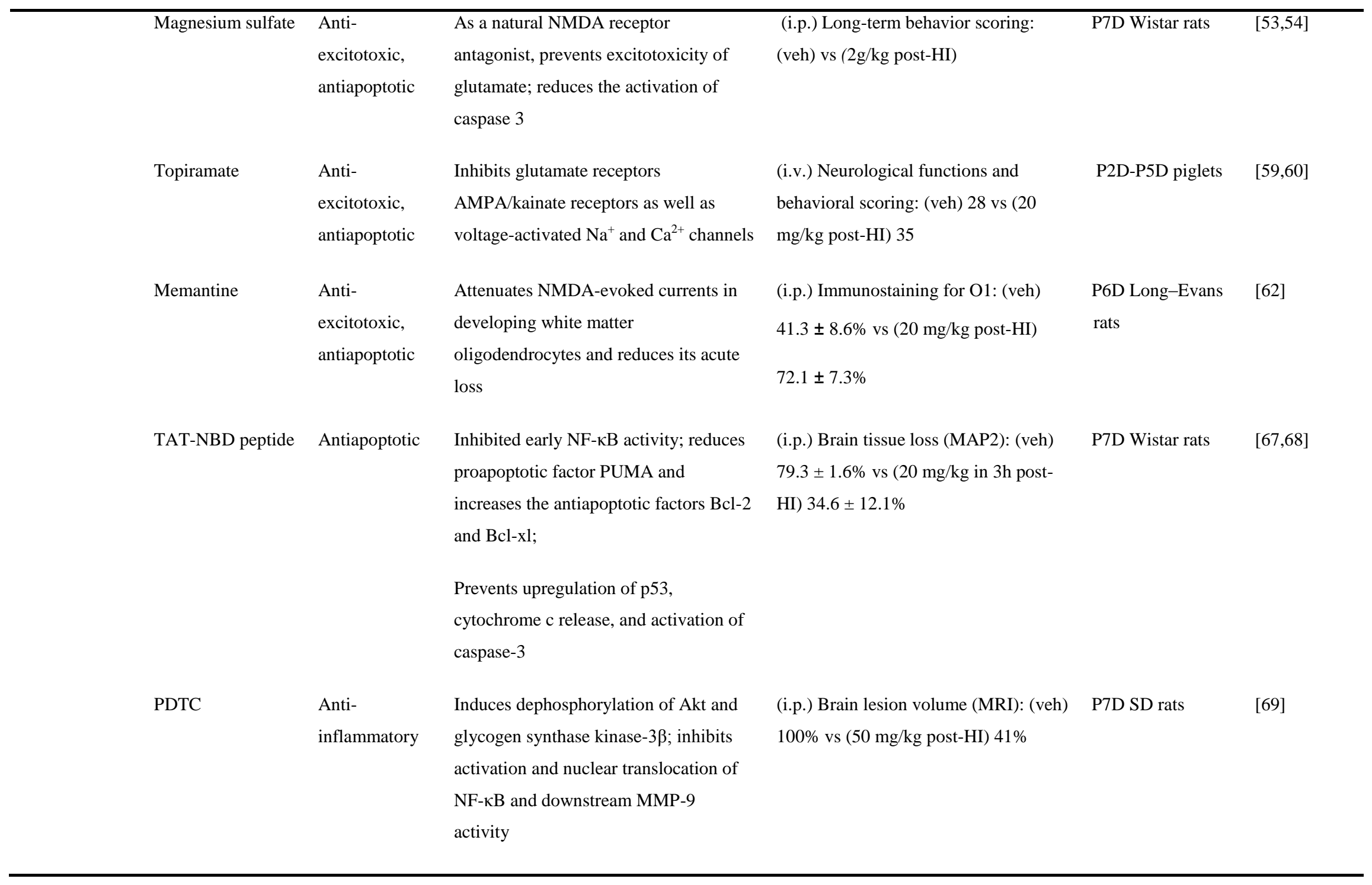




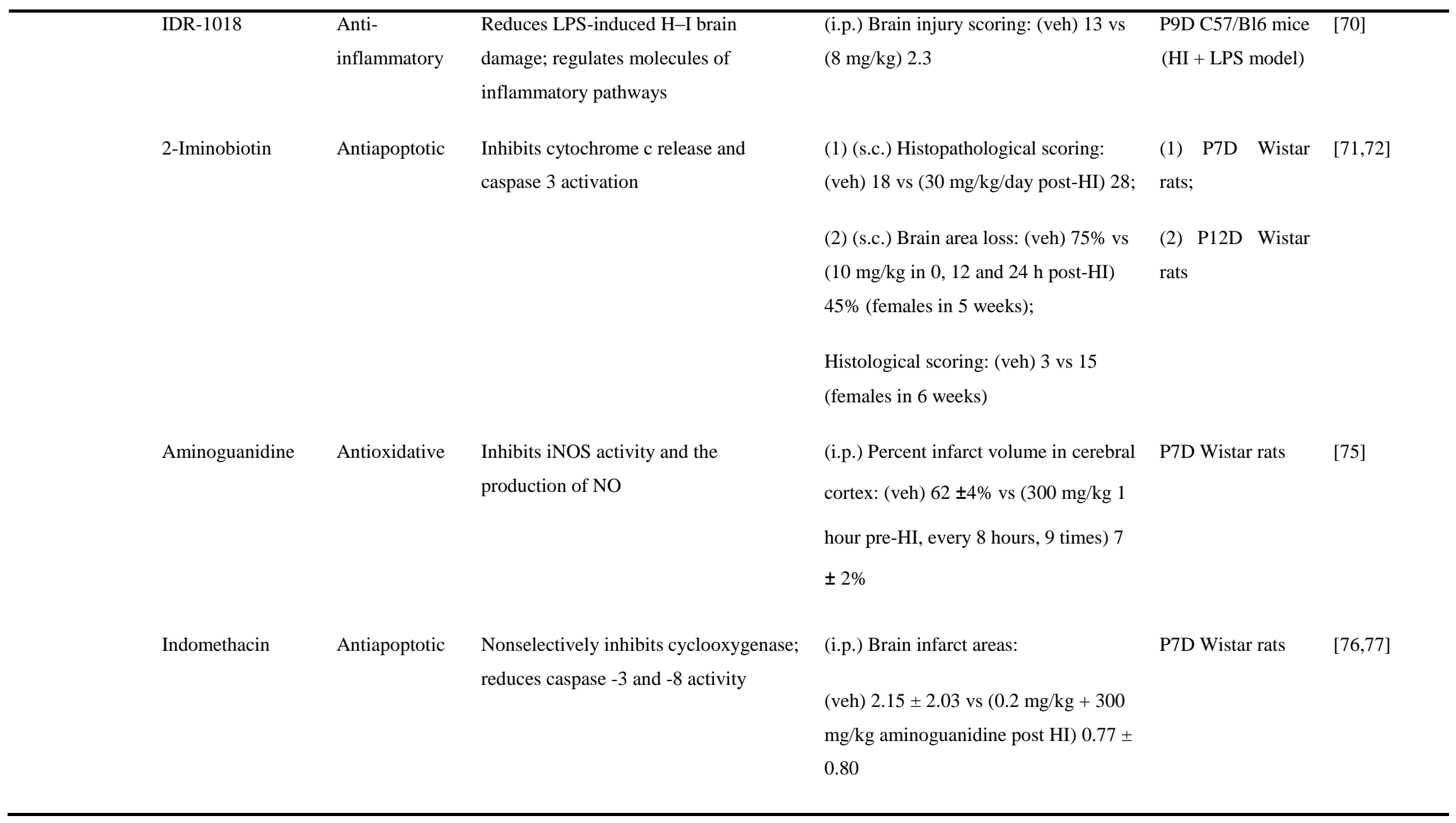




\begin{tabular}{|c|c|c|c|c|c|c|}
\hline & 7-Nitroindazole & Antioxidative & Selectively inhibits nNOS & (i.a.) Neurobehavioral scoring of P1 & E22D New & {$[78]$} \\
\hline & & & & kits: (veh) $20 \%$ normal vs $(0.1575$ & Zealand white & \\
\hline & & & & $\mu \mathrm{mol} / \mathrm{kg}$ pre and post-HI to mothers) & rabbits & \\
\hline & & & & $31 \%$ normal & & \\
\hline & JI-8 & Antioxidative & Selectively inhibits nNOS & (i.a.) Neurobehavioral scoring of P1 & E22D New & {$[78]$} \\
\hline & & & & kits: (veh) $20 \%$ normal vs $(0.1575$ & Zealand white & \\
\hline & & & & $\mu \mathrm{mol} / \mathrm{kg}$ pre and post-HI to mothers) & rabbits & \\
\hline & & & & $62 \%$ normal & & \\
\hline Later phase & & & & & & \\
\hline & BDNF & Neurotrophic & Binds to the TrkB and p75NTR & (i.c.v.) Histopathological scoring: & P7D SD rats & {$[83,85]$} \\
\hline & & & receptors, activates TrkB-ERK1/2 & (veh) $89 \%$ injury vs (10 $\mu$ g pre-HI) & & \\
\hline & & & signaling pathway & $50 \%$ injury; CA1 neuron counts: (veh) & & \\
\hline & & & & $58\left(\right.$ per $\left.15,000 \mathrm{~mm}^{2}\right)$ vs $(10 \mu \mathrm{g}$ pre-HI) & & \\
\hline & & & & 155 & & \\
\hline & IGF-1 & Neurotrophic & Enhances proliferation of neuronal and & (i.c.v.) Histopathological scoring & P4D SD rats & {$[86,87]$} \\
\hline & & & oligodendroglial progenitor cells; & (white matter damage) (veh) $82 \%$ vs & & \\
\hline & & & rescues oligodendrocyte progenitors & $(0.5 \mu \mathrm{g}$ post-HI) $50 \%$ & & \\
\hline & & & from glutamate-induced cell death & & & \\
\hline & bFGF & Neurotrophic & Enhances nestin and GAP-43 & (i.p.) Brain infarct volumes $\left(\mathrm{mm}^{3}\right)$ : & P7D SD rats $(\mathrm{HI}$ & [89-91] \\
\hline & & & expression in cortex, hippocampus and & (veh) $32.1 \pm 33.2$ vs $(100 \mu \mathrm{g} / \mathrm{kg} \times 3$ & model) & \\
\hline & & & extraventricular zone & post-HI) $11.5 \pm 17.1$ & & \\
\hline
\end{tabular}




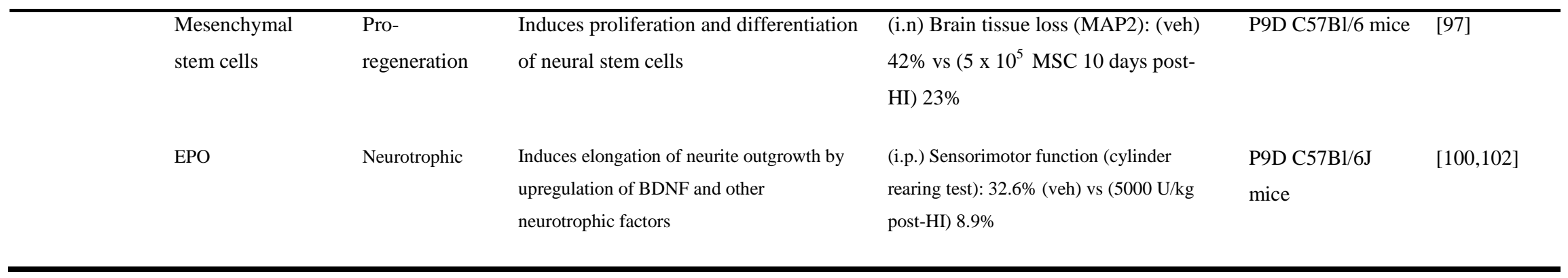

Table 2. Human trials for drug therapy in HIE

\begin{tabular}{|c|c|c|c|c|c|}
\hline $\begin{array}{l}\text { Therapeutic } \\
\text { drug }\end{array}$ & Study design & $\begin{array}{c}\text { Subjects } \\
\text { No. of babies }(n)\end{array}$ & Dose & $\begin{array}{c}\text { Outcome } \\
\text { (In treatment group) }\end{array}$ & Refs \\
\hline Xenon & $\begin{array}{l}\text { Phase } 1 \\
\text { single-arm, dose-escalation } \\
\text { study }\end{array}$ & $\begin{array}{l}\text { Total newborns }=14 \text { with } \\
\text { moderate and severe HIE }\end{array}$ & $\begin{array}{l}\text { Inhaled } 25 \% \text { or } 50 \% \text { xenon } \\
\text { for } 3,6,12 \text { or } 18 \text { hours }\end{array}$ & $\begin{array}{l}\text { No adverse respiratory or } \\
\text { cardiovascular effects at } 18 \text {-month } \\
\text { follow-up }\end{array}$ & {$[19]$} \\
\hline \multirow[t]{4}{*}{$\begin{array}{l}\text { Melatonin } \\
(\mathrm{Mel})\end{array}$} & $\begin{array}{l}\text { Prospective } \\
\text { Randomized study }\end{array}$ & $\begin{array}{l}\text { Total newborns }=30 \\
\text { Control } n=10\end{array}$ & $\begin{array}{l}10 \mathrm{mg} 2 \text { hourly orally for } 8 \\
\text { doses (total } 80 \mathrm{mg} \text { ) }\end{array}$ & $\begin{array}{l}\text { Reduction in malondialdehyde and } \\
\text { nitrite/nitrate levels }\end{array}$ & {$[33]$} \\
\hline & & Asphyxiated $n=10$ & & & \\
\hline & & Asphyxiated $+\operatorname{Mel} n=10$ & & & \\
\hline & $\begin{array}{l}\text { Randomized control pilot } \\
\text { study }\end{array}$ & $\begin{array}{l}\text { Total newborns }=30 \text { with } \\
\text { HIE undergoing hypothermia } \\
(\text { HT) }\end{array}$ & $\begin{array}{l}10 \mathrm{mg} / \mathrm{kg} \text { orally } \\
\text { daily for } 5 \text { days }\end{array}$ & $\begin{array}{l}\text { Reduction in oxidative stress; } \\
\text { Improved survival without } \\
\text { neurological or developmental } \\
\text { abnormalities at } 6 \text { months }\end{array}$ & {$[34]$} \\
\hline
\end{tabular}


HT group $n=15$

$\mathrm{HT}+\operatorname{Mel} n=15$

\section{Erythropoietin}

(EPO)
Phase 1

Multicenter, open-label, doseescalation study

Prospective case-control study

Total newborns $=45$

Control $n=15$

HIE $n=15$

$\mathrm{HIE}+\mathrm{EPO} n=15$

Randomized control trial

Total newborns $=167$

EPO $n=83$

Conventional $n=84$

Total of 114 newborns with mild/moderate or severe HIE

Meta-analysis of three
randomized/quasi-randomized

controlled trials

Randomized controlled multicenter trial

222 women in labor with fetal distress

Placebo $n=111$
$500 \mathrm{U} / \mathrm{kg}, 1000 \mathrm{U} / \mathrm{kg}$ and $2500 \mathrm{U} / \mathrm{kg}$ IV up to 6 doses

Dose $1000 \mathrm{U} / \mathrm{kg}$ well tolerated and produces plasma concentrations that are neuroprotective in animals

2500 IU/kg, subcutaneously, daily for 5 days

Improved EEG background and nitric oxide concentration at 2 weeks in EPO group

Improved neurologic and

developmental abnormality at 6

months

Reduced death or moderate/severe disability at 18 months

$500 \mathrm{U} / \mathrm{kg} n=31$

Once every other day IV for 2 weeks

$40 \mathrm{mg} / \mathrm{kg} / \mathrm{day}$ IV for 1 day (2 studies)

No difference in death or neurodevelopmental disability

$40 \mathrm{mg} / \mathrm{kg} /$ day IV for 3 days (1 study)

500 mg single IV dose

Maternal treatment did not significantly lower neuronal damage markers in cord blood 
Magnesium

sulfate

Meta-analysis of

5 randomized control trials
Topiramate

Autologous umbilical cord

blood cells
Randomized control trial (ongoing)

Phase I study for feasibility and safety
IV infusion of $250 \mathrm{mg} / \mathrm{kg}$ every $24 \mathrm{~h}$ for three doses

(2 studies), $250 \mathrm{mg} / \mathrm{kg}$ followed by two doses of

$125 \mathrm{mg} / \mathrm{kg}$ every $24 \mathrm{~h}$ for two doses (2 studies)

Single dose of $250 \mathrm{mg} / \mathrm{kg}$ (1 study)

Allopurinol $n=111$

Total of 182 newborns in 5

$10 \mathrm{mg} / \mathrm{kg}$ once daily for 3 days

IV infusion of engineered doses containing $1-5 \times 10^{7}$ nucleated cells adjusted for volume and red blood cells up to 4 doses
33 newborns with HIE undergoing hypothermia
Improvement in short-term outcomes without significant increase in sideeffects.

Trend toward increase in mortality in the magnesium group

Results awaited

Collection, preparation and infusion of fresh autologous cord blood is feasible with no significant clinical problems attributable to cells 